\title{
Settlements in unsaturated granular soils induced by changes in saturation and suction
}

\author{
Marius Milatz ${ }^{1, a}$, Tom Törzs ${ }^{1}$ and Jürgen Grabe ${ }^{1}$ \\ ${ }^{1}$ Institute of Geotechnical Engineering and Construction Management, Hamburg University of Technology, Hamburg, Germany
}

\begin{abstract}
In this contribution the hydro-mechanically coupled behaviour of a sand is experimentally investigated with the focus on settlements induced by changes in degree of saturation and suction. This phenomenon, referred to as collapse behaviour, is attributed to rearrangements of the grain skeleton due to changing capillary effects on wetting of the soil. For the experimental investigation of the collapse behaviour of a medium coarse sand cyclic dryingwetting tests are performed under oedometric conditions. In the test set-up a sand specimen, subjected to a constant small vertical stress, is cyclically dried and wetted by volume control of the pore water, whereas matric suction is measured using a tensiometer implemented to the specimen loading plate (topcap tensiometer). The test procedure, originally designed to investigate the hysteretic nature of the soil-water characteristic curve of the sand, allows to measure the one dimensional volume change of the specimen as evoked by the applied hydraulic paths under constant net stress. By varying the specimen void ratio the impact of density on the collapse behaviour can be assessed. The test data is important for the development of a mechanical constitutive model which can take the volume change behaviour due to suction changes into account.
\end{abstract}

\section{Introduction}

The hydraulic and mechanical behaviour of unsaturated soils is closely related due to capillary effects. These effects, which can either be attributed to an averaged macroscopic capillary pressure or to micromechanical menisci forces caused by surface tension of pore water, influence the stress state of the grain skeleton and therefore also the shear strength and volume change behaviour of the soil. When the soil encounters a change in degree of saturation or suction, e. g. due to infiltration, the capillary effects vary, which has an impact on the mechanical behaviour. Especially for cohesive soils a pronounced volume change is encountered due to changes of the hydraulic state with the soil swelling on wetting and shrinking or even cracking on drying. This volume change behaviour is an important research issue when structural damage to foundations or leakage through low permeability barrier materials is of concern.

An early approach to capture the volume change behaviour of unsaturated cohesive soils was presented by Matyas and Radhakrishna (1968), who described volume change by state surfaces in the net stress-suction-void ratio space. From the results a metastable structure with collapse behaviour induced by changes in matric suction and an influence of hysteresis could be deduced (Fredlund \& Rahardjo 1993).

The volume change behaviour of cohesive materials has also been investigated experimentally by Sharma and Wheeler (2000) with a special focus on drying-wetting cycles. The results indicate irreversible compression during drying of the investigated specimens and an influence of hysteresis.

The volume change effects of granular soils are typically less pronounced, although settlement behaviour has been observed for loose sands due to wetting, which is referred to as capillary collapse. The observed volume change is attributed to microstructural effects. These are given for example, when the grain skeleton adopts a more stable state as the capillary forces change.

Bruchon et al. (2013) used X-ray Computer Tomography (CT) to analyze changes in the threedimensional grain skeleton structure upon wetting of a sand. In their tests a small cylindrical specimen of loose sand was wetted from the bottom with a hanging water column technique and simultaneously scanned in a CTdevice. The results indicated that the local collapse behaviour is related to the coalescence of capillary bridges in the grain skeleton upon wetting.

In order to describe the volume change behaviour of unsaturated soils by constitutive laws, an effective stress relation is needed. With the enhanced effective stress principle for unsaturated soils, presented by Bishop (1959) in the form of equation 1, the partial pressures of pore air, $u_{\mathrm{a}}$, and pore water, $u_{\mathrm{w}}$, can be incorporated. Weighted by the Bishop-parameter $x$, the influence of capillary pressure or suction, $s=u_{\mathrm{a}}-u_{\mathrm{w}}$, on effective stress can be considered.

$$
\sigma^{\prime}=\sigma-u_{\mathrm{a}}+\chi\left(u_{\mathrm{a}}-u_{\mathrm{w}}\right)
$$

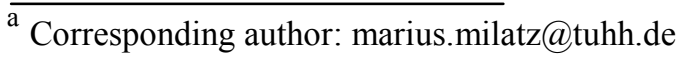


Bishop stress is widely used to describe the stress state of unsaturated soils and has also been applied to calculate shear strength with the Mohr-Coulomb limit state equation. It is known to predict the increase in shear strength well for some soils, which has been investigated by triaxial testing (Bishop, 1961; Bishop \& Blight, 1963). However, an assumption for the parameter $x$ has to be made. This parameter is usually assumed to be equal to the degree of saturation $\left(\mathrm{x}=S_{\mathrm{r}}\right)$ or the effective degree of saturation $\left(\mathrm{X}=S_{\mathrm{e}}\right)$. In other cases different and more complex relationships are assumed. The role and shape of the $x$-parameter is frequently discussed in literature (e. g. Pereira et al., 2011).

As it was found that Bishop stress was not always able to capture shear strength and volume change at the same time, Fredlund and Morgenstern (1977) developed the principle of two independent stress state variables. The use of either one or two stress state variables for the modelling of the constitutive behaviour of unsaturated soils is discussed by Jommi (2000). When two stress state variables, e. g. net stress, $\sigma-u_{\mathrm{a}}$, and suction, $u_{\mathrm{a}}-u_{\mathrm{w}}$, are used, the influence of changes in net stress and suction on the constitutive behaviour can be separated. This allows to model volume change at constant net stress induced by suction changes.

Up to today the coupling mechanisms are not fully understood and no model has been found to describe both stress state and volume change behaviour properly at the same time for different soil types Jommi (2000).

In this contribution an experimental method is presented to study the coupling effects in granular soils leading to settlements as a result of changes in saturation and suction, in order to gather more data on this phenomenon. The measured results will be interpreted in terms of changes of the effective stress for unsaturated soils and may be used in further studies to develop or improve a constitutive model to take the hydromechanical coupling into account.

\section{Experimental investigation of settle- ment behaviour}

\subsection{Investigated soil}

In continuation of a research project on unsaturated granular soils as subgrade materials for sites of container handling in ports and the influence of repeated vehicle loads (Grabe and Milatz, 2014) a medium coarse sand from Container Terminal Burchardkai (CTB) at the Port of Hamburg was investigated. This sand is of sedimentary origin from the river Elbe at Hamburg and is used as backfilling material for quay wall construction. In different experiments the hydraulic and hydromechanical behaviour of this sand has been investigated (Milatz, 2013; Milatz and Grabe, 2014; Milatz and Grabe, 2015; Milatz, 2015). The same sand will be investigated in the studies presented in this contribution with the focus on hydro-mechanical coupling and settlements induced by changes in the hydraulic state.
Selected soil parameters of CTB-sand are summarised in table 1.

Table 1. Selected soil parameters of CTB-sand.

\begin{tabular}{c|c|c|c|c|c}
$\boldsymbol{\rho}_{\mathbf{s}}$ & $\boldsymbol{e}_{\min }$ & $\boldsymbol{e}_{\max }$ & $\boldsymbol{d}_{\mathbf{1 0}}$ & $\boldsymbol{d}_{\mathbf{m a x}}$ & $\boldsymbol{U}$ \\
\hline$\left(\mathrm{kg} / \mathrm{m}^{3}\right)$ & {$[-]$} & {$[-]$} & {$[\mathrm{m}]$} & {$[\mathrm{m}]$} & {$[-]$} \\
\hline 2650 & 0.41 & 0.86 & $1.6 \mathrm{e}-4$ & $2 \mathrm{e}-3$ & 2.4 \\
\hline
\end{tabular}

$\rho_{\mathrm{s}}$ : grain density, $e_{\min }:$ minimum void ratio

$e_{\max }$ : maximum void ratio

$d_{10}$ : grain diameter at $10 \%$ passing

$d_{\text {max }}$ : maximum grain diameter, $U$ : uniformity index

The main findings on the hydraulic behaviour of CTBsand are its low capillarity with a void ratio-dependent air entry value (AEV) of the soil-water characteristic curve of 2.5 to $3 \mathrm{kPa}$ and a pronounced hysteretic behaviour with air entrapment on drying-wetting cycles (Milatz, 2015; Törzs, 2015).

\subsection{Test set-up and testing procedure}

In Milatz and Grabe (2014) and Milatz and Grabe (2015) a simple shear device was presented that allows to control and measure matric suction in unsaturated sand specimens on shearing. For this purpose a vacuum method for suction control was applied and a topcap tensiometer implemented to the simple shear apparatus. This method was enhanced to study the drying-wetting behaviour in cylindrical sand specimens under oedometric stress conditions for cyclic hydraulic paths in Milatz (2015) and Törzs (2015). In the executed hydraulic tests on sand specimens with a diameter of 50 $\mathrm{mm}$ and initial height of $20 \mathrm{~mm}$ a pore water volume change was prescribed with a computer-controlled enhanced precision pore water pressure controller (GDS Instruments). The specimen matric suction response due to the applied changes in saturation was measured with a topcap tensiometer. With the help of this testing procedure the hysteretic paths of the soil-water characteristic curve could be investigated. The test results show a negligible relationship between the applied flow velocity and the measured hydraulic paths (Törzs, 2015). In the hydraulic tests presented in Törzs (2015) the original flat ceramic disc of the topcap tensiometer used in the simple shear tests was modified and changed to a pointy ceramic tip that pierces into the core of the cylindrical sand specimens. This method, meant to improve hydraulic contact and to measure a mean suction value, was adopted in the studies presented in this paper. The full test setup is represented in figure 1. A comparison of the two existing topcap tensiometers is shown in figure 2.

The sand specimens are dewatered through the base, in which a microporous membrane (Pall Corp.) with pore diameter of $0.8 \mu \mathrm{m}$ is clamped. This filter membrane method represents an alternative to ceramic discs and has already been used by Nishimura et al. (2012) to measure the SWCC. In the case of this study the filter membrane is important, because the pore water volume-controlled 
testing requires a high hydraulic conductivity of the specimen interface to the dewatering system. The dewatering system connected to the pore pressure controller is initially filled with deaired water. The filter membrane is also deaired and wetted by placing it in a vacuum chamber. The test set-up allows to prescribe hydraulic paths to the investigated sand specimen, in order to investigate different paths of the soil-water characteristic curve. When a sand specimen is dryed from the bottom, the pore space is filled with air which can pass through holes in the topcap. Therefore, it is assumed that the pore air pressure is equivalent to the atmospheric pressure $\left(u_{\mathrm{a}}=0\right)$, resulting in a matric suction equivalent to the negative pore water pressure $\left(s=-u_{\mathrm{w}}\right)$. The negative pore water pressure is then directly measured with the topcap tensiometer.

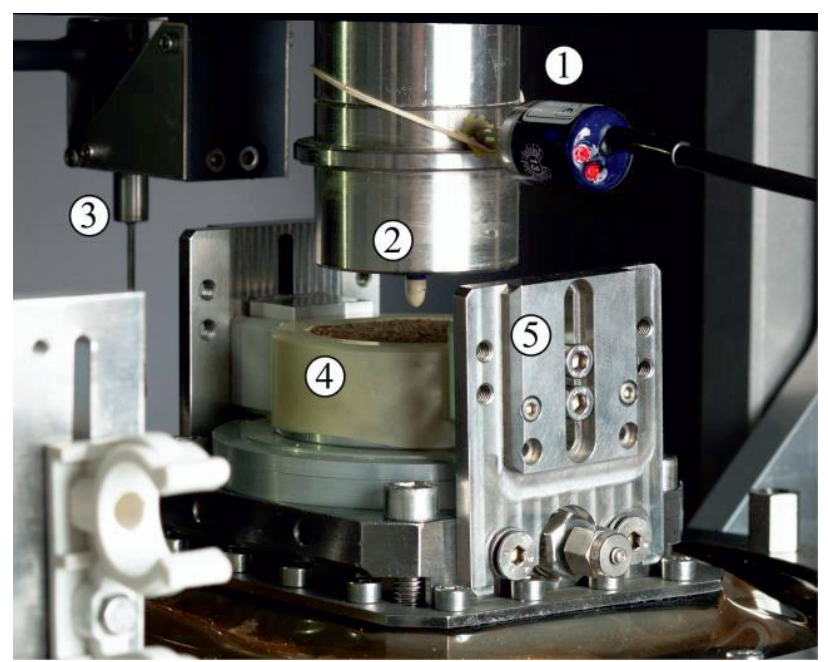

Figure 1. Test set-up for the hydraulic tests on CTB-sand. 1: T5 Laboratory tensiometer (UMS GmbH, Munich), 2: Topcap with pointy ceramic tensiometer tip, 3: LVDT, 4: Cylindrical sand specimen in aluminium cylinder and latex membrane, 5: Membrane holder.

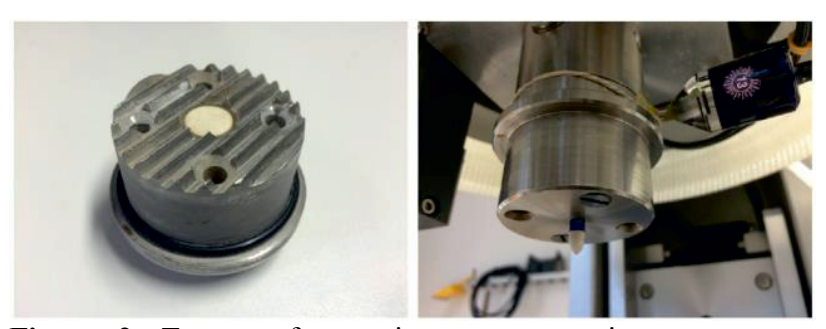

Figure 2. Topcaps for tensiometer connection to measure matric suction in cylindrical sand specimens. Left: Toothed topcap with a flat ceramic disc used in simple shear tests. Right: Topcap with a pointy ceramic tip used for the tests on hydromechanical coupling in the present study.

Typical results of a hydraulic test with cyclic hydraulic loading using the topcap tensiometer with the flat ceramic disc from Milatz (2015) are represented in figure 3. It can be seen that the test results from conventional methods to obtain the soil-water characteristic curve are well reproduced. Furthermore, the hysteretic behaviour can be investigated thoroughly.

In this study, however, the hydro-mechanical coupling is of interest. In order to capture specimen volume change induced by changes in the hydraulic state, an LVDT with high accuracy of $\pm 0,005 \mathrm{~mm}$ is used (compare figure 1).

The sand specimens are prepared by pluviating dry sand into the water filled test container. For looser specimens with a high initial void ratio $e_{0}$ no compaction was applied, whereas specimens with higher initial density were achieved by compacting them on a vibrating table during specimen preparation. The topcap is then lowered down onto the specimen top using a load-controlled docking procedure. The docking is completed, when a vertical stress of $10 \mathrm{kPa}$ is reached. This small stress level was found to be enough for the tensiometer tip to penetrate into the middle of the sand specimens as shown in figure 1 . In a second test step the vertical stress level is linearly ramped to $25 \mathrm{kPa}$ for all specimens and then kept constant in the following test steps. This small stress level is selected in order to reduce the initial settlements and changes in void ratio due to consolidation.

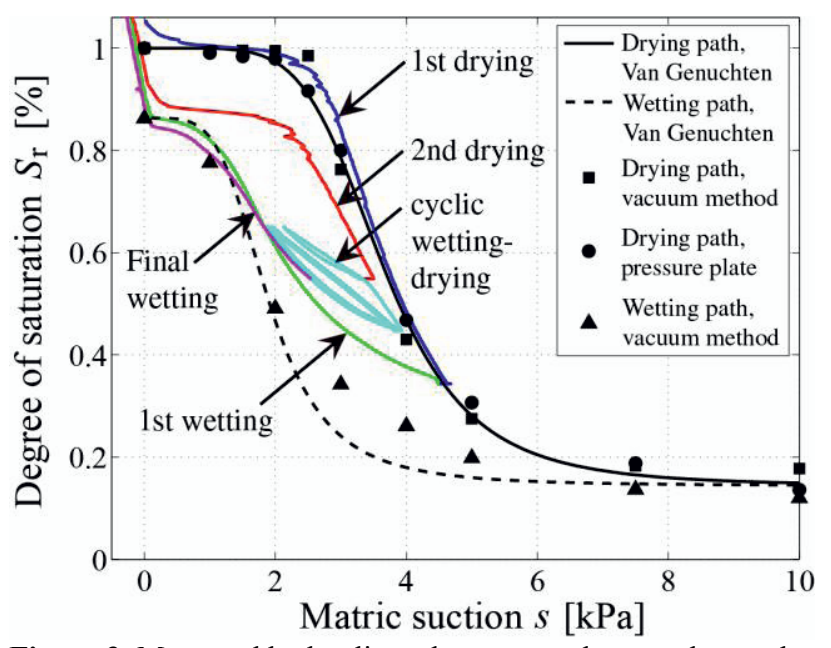

Figure 3. Measured hydraulic paths compared to test data and calculated data using the Van Genuchten (1980) model for CTB-sand with $e_{0}=0.5$ from Milatz (2015).

After application of vertical stress and equilibration of all settlements, three drying-wetting cycles are prescribed. For this purpose the pore water volume is removed and added linearly over time using the pore water pressure controller and a flow velocity of 0.5 to $5 \mathrm{~mm}^{3} / \mathrm{s}$. The hydraulic test steps begin with a first drying stage, in which $S_{\mathrm{r}}$ is reduced to 0.3 . It was found that this degree of saturation seems to represent a limit for accurate tensiometer measurements due to a loss of hydraulic contact with the tensiometer tip and the pore water phase. In this case a further drying of the sand specimens leads to oscillating tensiometer measurements. Furthermore, test results indicate that this failure of the topcap tensiometer appears to be more pronounced for very dense specimens.

On rewetting of the sand specimens significant air entrapment was discovered with an air degree of saturation $S_{\mathrm{a}}=1-S_{\mathrm{r}} \approx 0.18$ reached after the first wetting path (Milatz, 2015). Therefore, the sand specimens are rewetted only up to $S_{\mathrm{r}}=0.82$ to avoid over-saturation. However, this air degree of saturation turns out not to be a constant, because the volume of entrapped air appears to increase during cyclic drying-wetting and to converge 
asymptotically to a residual air degree of saturation. The target values of $S_{\mathrm{r}}$ are used to calculate the pore water volume change to be prescribed by the pressure controller. In these calculations as well as in the overall data evaluation a volume change of the specimens due to settlements is taken into account, because it leads to changes in $S_{\mathrm{r}}$ during the test. The drying-wetting cycles with $0.3 \leq \mathrm{Sr} \leq 0.82$ are repeated twice resulting in a total of three drying-wetting cycles.

In the selected tests presented in this contribution, the void ratio was varied, in order to capture the influence of density on hydro-mechanical coupling due to cyclic changes in suction and degree of saturation. The initial void ratios $e_{0}$ and void ratios after the initial consolidation stage $e_{1}$, which represent the true initial values at the start of the hydraulic test stage, are summarized in table 2.

Table 2. Specimens of CTB-sand with different initial void ratios for tests on the hydro-mechanical coupling.

\begin{tabular}{c|c|c} 
Specimen no. & $\boldsymbol{e}_{0}[-]$ & $\boldsymbol{e}_{\mathbf{1}}[-]$ \\
\hline 1 & 0.69 & 0.66 \\
\hline 2 & 0.64 & 0.62 \\
\hline 3 & 0.56 & 0.54 \\
\hline
\end{tabular}

$\boldsymbol{e}_{0}$ : initial void ratio, $\boldsymbol{e}_{1}$ : void ratio after consolidation

\section{Test results}

\subsection{Suction response of topcap tensiometer}

Before the tests the topcap tensiometer was filled with deaired water and checked for response time and accuracy by applying negative pore water pressure steps with a vacuum controller. The results indicate a quick sensor response and good accuracy at low suction, as represented in figure 4 .

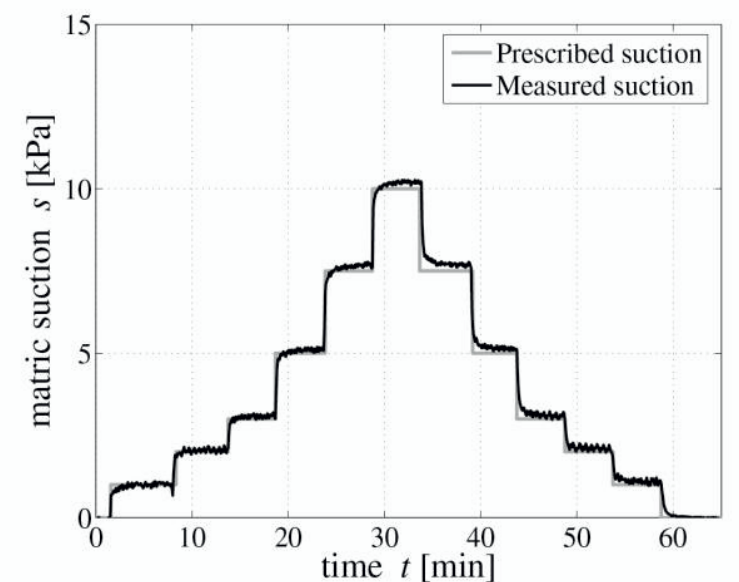

Figure 4. Suction response of the topcap tensiometer in a test procedure using a vacuum controller.

The prescribed changes in degree of saturation and a typical measured suction response versus test time for sand specimen 1 at $e_{0}=0.69$ are represented in figure 5 . It can be seen that a characteristic suction response behaviour is measured. Under the assumption that the degree of saturation, calculated from the outflow and inflow data, and the measured matric suction are representative values for the whole sand specimen, the hydraulic paths of the soil-water characteristic curve can be plotted as represented in figure 6 .

The soil-water characteristic curve shows the typical hysteretic behaviour. It can be seen that the entrapped air volume increases after each wetting cycle. Different studies (Milatz, 2015; Törzs, 2015) demonstrate that the soil-water characteristic curve of the investigated CTB-sand is well reproduced compared to conventional methods, such as the pressure plate technique or vacuum method. The method can be used to investigate different hydraulic paths, which can be easily prescribed with the available hydraulic functions for water volume flow of the pore water pressure controller. However, the method seems to be limited to $S_{\mathrm{r}} \geq 0.3$. Unfortunately, a good suction response was not given in all tests. It was noticed that for specimen 3 with the smallest initial void ratio the tensiometer showed oscillations and often the hydraulic contact appeared to be lost.

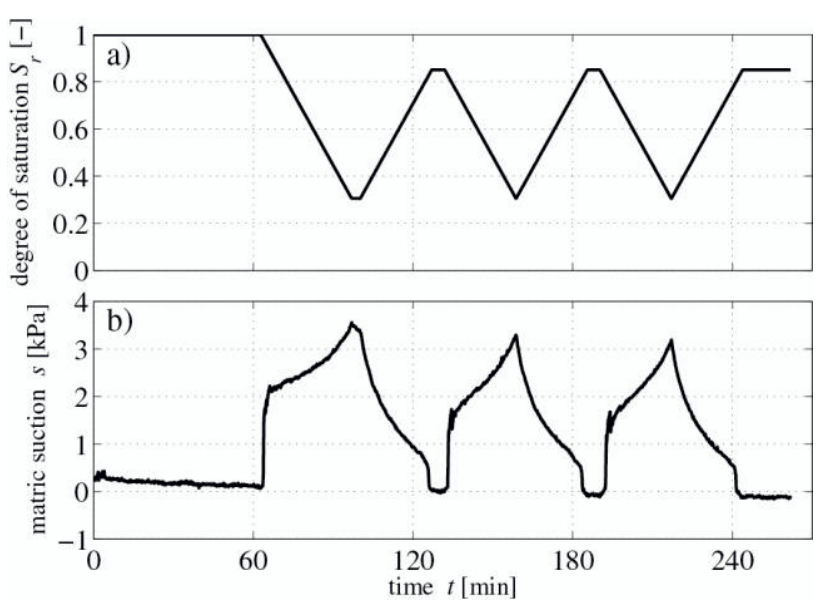

Figure 5. a) Prescribed change in degree of saturation and b) measured matric suction versus time in the hydraulic test on a sand specimen with $e_{0}=0.69$.

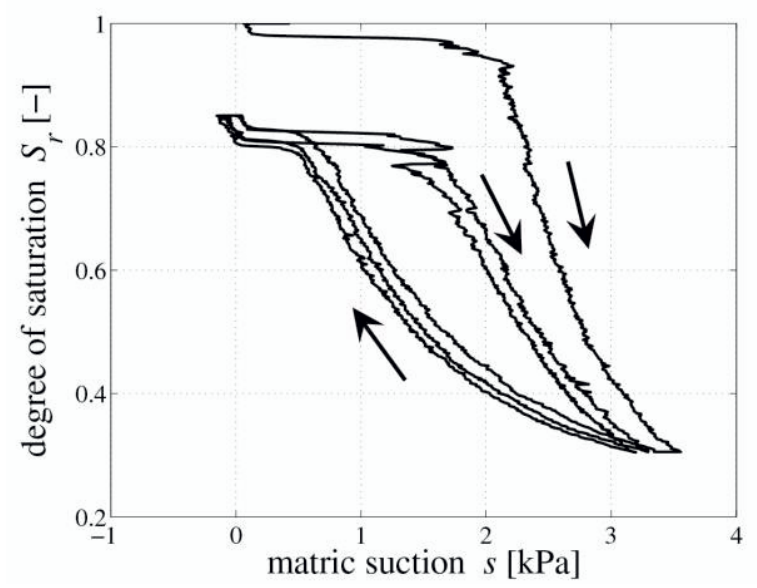

Figure 6. Measured hydraulic paths of the soil-water characteristic curve in the $s-S_{\mathrm{r}}$ plane for the sand specimen with $e_{0}=0.69$. 


\subsection{Settlements induced by changes in satura- tion and suction}

The hydraulic test steps allowed to measure the volume change behaviour during cyclic drying and wetting. In all cases a typical volume change pattern was noticed as represented in figure 7 for sand specimen 1 with $e_{0}=0.69$. It can be seen that the main changes in void ratio due to settlements under constant vertical stress occur on rewetting of the specimen shortly before $S_{\mathrm{r}}=0.82$ as the maximum degree of saturation after air entrapment is reached. When plotted versus measured suction, the volume changes closely coincide with a suction drop to zero. For a second and third rewetting the volume change becomes smaller. This behaviour could be observed for all selected specimens.

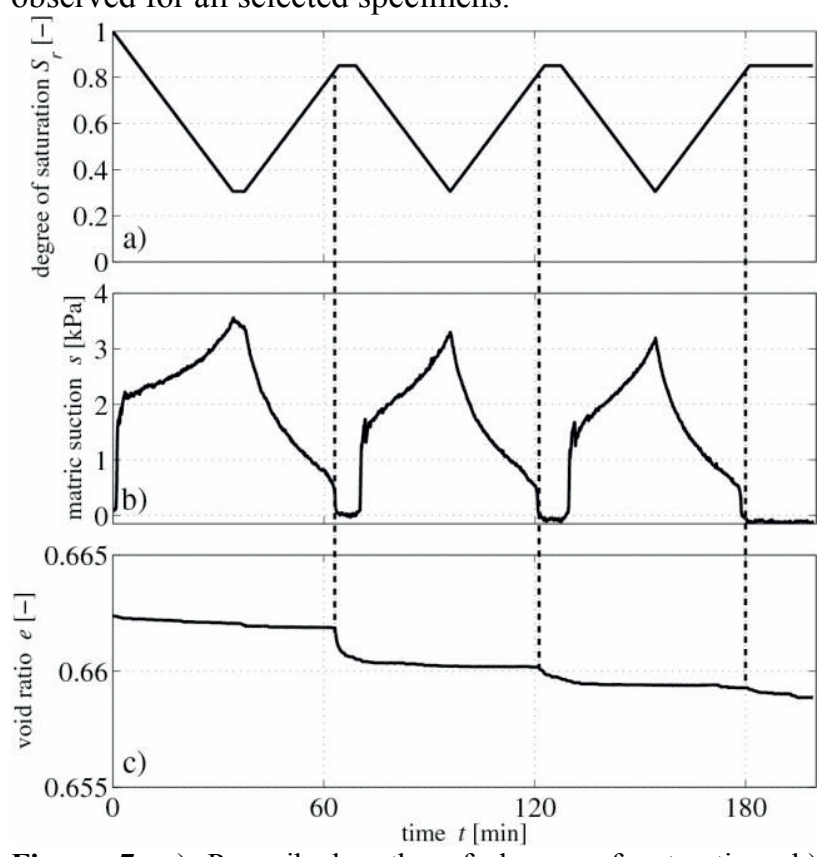

Figure 7. a) Prescribed paths of degree of saturation, b) measured matric suction and c) changes in void ratio calculated from measured settlements for a sand specimen with $e_{0}=0.69$.

The influence of changes in degree of saturation and measured matric suction on volume change of the sand are further emphasized when the axial strain of different specimens is plotted over degree of saturation or matric suction as represented in figures 8 and 9. The recorded volume change can be directly related to changes in $S_{\mathrm{r}}$ and $s$. For all specimens a very slight increase in compressive axial strain (negative mathematical sign) can be noticed during drying. However, the compressive axial strain mainly increases during wetting. The increase in axial strain is not equally pronounced in all cases and a clear relationship to the initial void ratio cannot be found, when the presented tests are considered. An example of this is the relatively small volume change for specimen 1 with the highest initial void ratio of $e_{0}=0.69$ which may represent an outlier.

When the change of theoretical Bishop effective stress $\Delta \sigma^{\prime}=s \times$ with $\chi=S_{\mathrm{r}}$ according to equation 1 is considered in figure 10 , the resulting paths in the $\Delta \sigma^{\prime}-\varepsilon-$ plane resemble oedometric loading and unloading paths. However, the mechanical response seems to be inversed compared to the observed behaviour when total stress is applied to the specimen. In the case of small changes in $\Delta \sigma^{\prime}$ a very high stiffness is observed for loading (increase of $\Delta \sigma^{\prime}$ ) and a small stiffness for unloading (decrease of $\left.\Delta \sigma^{\prime}\right)$.

Although the applied stresses and measured axial strains are very small and maybe suffer from errors of measurement or specimen preparation, the observed behaviour indicates some intergranular phenomena occurring due to changes in degree of saturation and suction. The results clearly show that an increase in $\Delta \sigma$ ' has a smaller effect on volume change than its decrease. Obviously, also the hydraulic hysteresis is of importance. On the micromechanical scale the results maybe an indication that the rewetting of the grain skeleton leads to restructuring of singular grains, because the menisci or water-air-interfaces change. With a further reduction of void ratio the hydro-mechanical coupling effects seem to be reduced, which can be deduced from the decreasing axial strains. The product of matric suction and degree of saturation $\Delta \sigma$ ' $=s S_{\mathrm{r}}$, referred to as "suction stress" by Lu and Likos (2006), can be used to describe the micromechanical changes in intergranular stress on a macroscopic scale.

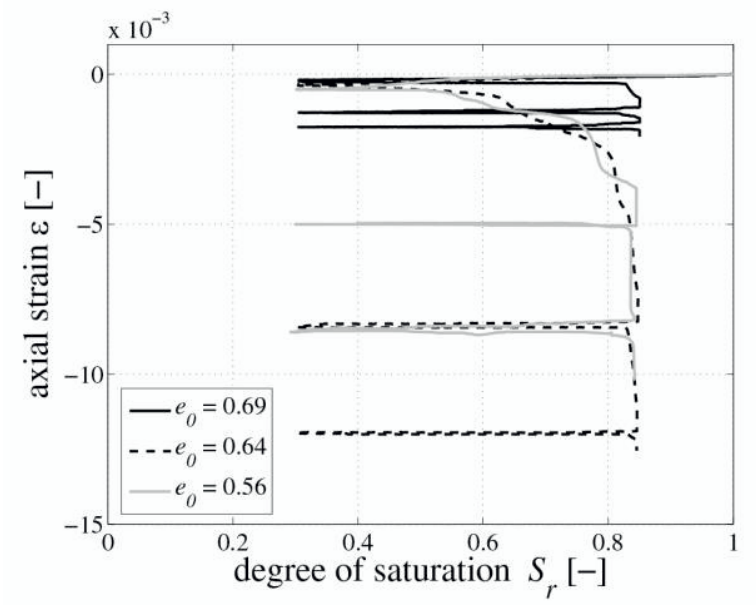

Figure 8. Axial strain versus degree of saturation for sand specimens with different initial void ratios in the hydraulic test stage with three drying-wetting cycles.

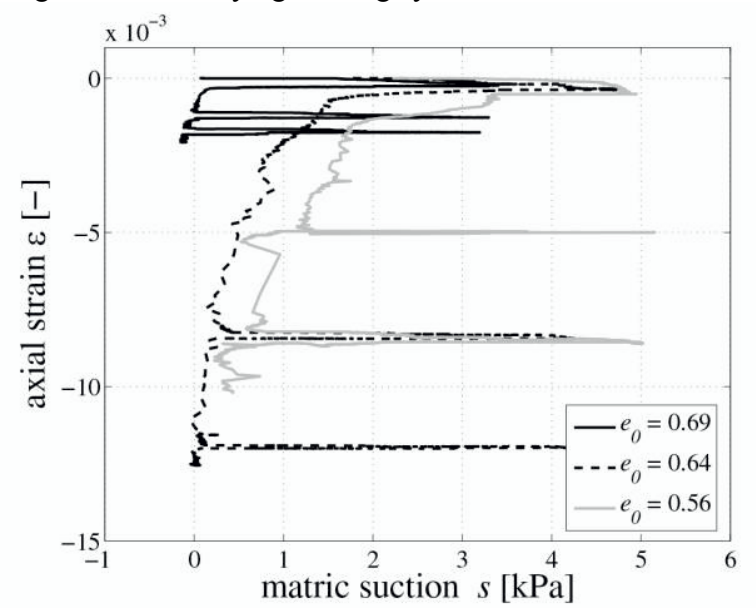

Figure 9. Axial strain versus measured matric suction for sand specimens with different initial void ratios in the hydraulic test stage with three drying-wetting cycles. 
It is interesting to notice that unlike most cohesive soils, the investigated sand specimen only encounters a negative volume change due to increasing settlements. The effect of swelling on rewetting, as described and modelled e. g. by Wheeler et al. (2003) for cohesive soils, is irrelevant for the sand. Compared to a cohesive soil, where the electro-chemical bonds are additionally influenced by changes in degree of saturation, leading to a pronounced volume change behaviour, the sand encounters only weak capillary effects, which directly interact with the grain skeleton. Under gravity and constant normal stress, coarse grain skeletons will develop states of higher density which are more stable compared to looser initial grain structures, when single particles are restructured due to changes in the hydraulic state.

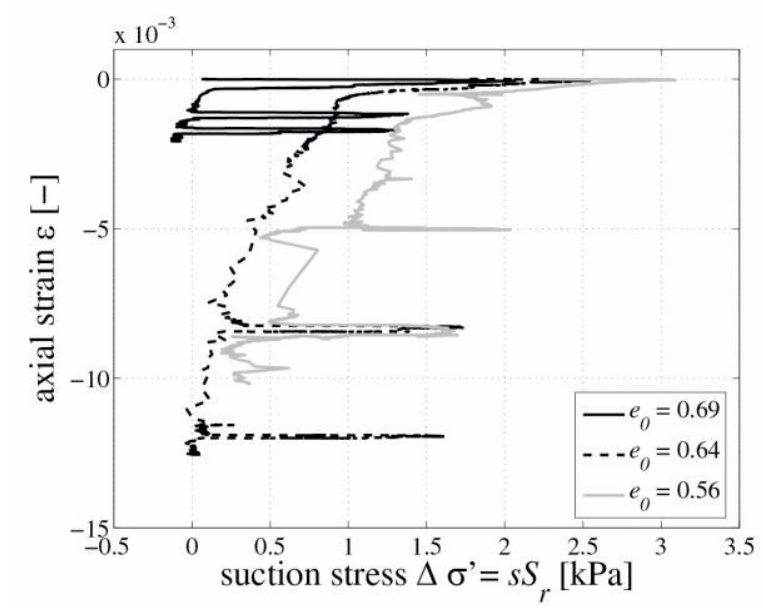

Figure 10. Axial strain versus change in effective stress $\Delta \sigma^{\prime}=$ $s \chi\left(\mathrm{X}=S_{\mathrm{r}}\right)$ for sand specimens with different initial void ratios in the hydraulic test stage with three drying-wetting cycles.

\section{Summary and outlook}

In this contribution selected results of different tests on the hydro-mechanical coupling of an unsaturated medium coarse sand have been presented. In the presented tests sand specimens under oedometric stress state have been investigated by prescribing pore water volume-controlled changes in degree of saturation and by applying simultaneous suction measurements with a tensiometer. It could be shown that the presented test method, originally meant to investigate the hysteretic nature of the soil-water characteristic curve of sandy soils, can be expanded to study specimen settlements induced by changes in degree of saturation and suction.

The results indicate that changes in the unsaturated stress state lead to settlements on rewetting. These can be related to changes in the contribution of suction and degree of saturation to Bishop effective stress. The settlements due to an increase in suction stress $\Delta \sigma^{\prime}=s S_{\mathrm{r}}$ on drying of the sand specimens are small compared to the effect of wetting paths. The results show a collapselike behaviour on rewetting, which may be due to a restructuring of single grains as the capillary menisci change on wetting.

In the future it is planned to evaluate further hydraulic paths controlled with the presented test setup to investigate the influence of void ratio and also normal stress state which was not varied in the selected tests presented in this paper. The expected further results may help to better understand the volume change behaviour of coarse grained soils in the unsaturated state and can be used for the enhancement of existing constitutive models or for the design of new ones that can take the observed coupled effects into account.

\section{References}

Bishop, A. W. (1959). The principle of effective stress. Teknisk Ukeblad, 106 (39), 859-863.

Bishop, A.W. (1961). The experimental study of partly saturated soil in the triaxial apparatus. In: Proc. of 5th International Conference on Soil Mechanics, Paris, pp. 13-21. Bishop, A. W. \& G. E. Blight (1963). Some aspects of effective stress in saturated and partly saturated soils. Géotechnique 13, 177-197.

Bruchon, J.-F., J.-M. Pereira, M. Vandamme, N. Lenoir, P. Delage, \& M. Bornert (2013). Full 3d investigation and characterisation of capillary collapse of a loose unsaturated sand using x-ray ct. Granular Matter 15, 783-800.

Fredlund, D. G. \& N. R. Morgenstern (1977). Stress state variables for unsaturated soils. ASCE J. Geotech. Eng. Div. GT5 103, 447-466.

Fredlund, D. G. \& H. Rahardjo (1993). Soil mechanics for unsaturated soils. John Wiley \& Sons.

Grabe, J. \& M. Milatz (2014). The change of matric suction due to heavy vehicle crossing. In: Proc. of 6th International Conference on Unsaturated Soils (UNSAT 2014), 2-4 July 2014. Sydney, Australia, Volume 2, pp. 1431-1437.

Jommi, C. (2000). Remarks on the constitutive modelling of unsaturated soils. In: A. Tarantino and C. Mancuso (Eds.), Experimental evidence and theoretical approaches in unsaturated soils., pp. 139-153. Rotterdam: Balkema.

Lu, N. \& W. J. Likos (2006). Suction stress characteristic curve for unsaturated soil. Journal of Geotechnical and Environmental Engineering 132 (2), 131-142.

Matyas, E. L. \& H. S. Radhakrishna (1968). Volume change characteristics of partially saturated soils. Géotechnique 18, 432-448.

Milatz, M. (2013). On the control of low negative water pressures in laboratory tests on unsaturated sand. In: Proc. of 5th International Young Geotechnical Engineers' Conference (iYGEC), Paris, France, pp. 55-58.

Milatz, M. (2015). An experimental method to study the dryingwetting behaviour of a sand. In: Proc. of 6th Asia-Pacific Conference on Unsaturated Soils (AP-UNSAT 2015). (Paper accepted for publication).

Milatz, M. \& J. Grabe (2014). Triaxial and simple shear tests on unsaturated sand specimens with negative pore water pressures. In: Proc. of 6th International Conference on Unsaturated Soils (UNSAT 2014), 2-4 July 2014, Sydney, Australia, Volume 2, pp. 1631-1637.

Milatz, M. \& J. Grabe (2015). A new simple shear apparatus and testing method for unsaturated sands. Geotechnical Testing Journal 38, 9-22.

Nishimura, T., J. Koseki, D. G. Fredlund, \& H. Rahardjo (2012). Microporous membrane technology for measurement of soil-water characteristic curve. Geotechnical Testing Journal 35 (1), 1-8.

Pereira, J. M., O. Coussy, E. E. Alonso, J. Vaunat, \& S. Olivella (2011). Is the degree of saturation a good candidate for bishop's X-parameter? In: E. E. Alonso and A. Gens (Eds.), Proc. of 5th International Conference on Unsaturated Soils, pp. 913-919. 
Sharma, R. S. \& S. J. Wheeler (2000). Behaviour of an unsaturated highly expansive clay during cycles of wetting and drying. In: Proc. of 1st Asian Conference on Unsaturated Soils (UNSAT-ASIA 2000), Singapore, pp. 721-726.

Törzs, T. (2015). Experimental and numerical investigations on moisture transport in unsaturated soils. Master thesis, Institute of Geotechnical Engineering and Construction Management, Hamburg University of Technology. (Unpublished).

Wheeler, S. J., R. S. Sharma, \& M. S. R. Buisson (2003).

Coupling of hydraulic hysteresis and stress-strain behaviour in unsaturated soils. Géotechnique 53 (1), 41-54. 